\title{
Parent-Child Interaction and Pre-Schooler's Level of Writing Readiness
}

\author{
Daniel Achero Rabok* Dr. Teresa Bitengo Mwoma \\ School of Education, Early Childhood and Special Needs Education Department, Kenyatta University, \\ P.O Box 22546-00400, Nairobi, Kenya.
}

\begin{abstract}
Parenting education programmes have been found to promote good parent-child interactions in their households. Consequently, benefits in academic success, proper development of a child, prevention of child maltreatment and child aggression, have been associated with these programs. This article reports findings of the study conducted in Siaya county, Kenya to establish whether parenting education programmes influence writing readiness skills of children. A sample comprising 196 caregivers and their preschool children participated in the study. Questionnaire and learners' writing tests were used to collect data from caregivers and preschool children respectively. To ensure validity of the instruments, content analysis was done. Descriptive statistics including means, standard deviation and percentages were used in summarizing data while Pearson Product Moment correlation coefficient was used to analyse the data with the help of Statistical Package for Social Sciences version 20. The study revealed an existence of a significant relationship between parent-child interactions and level of writing readiness of preschool children.
\end{abstract}

Keywords:Children's writing skills, parental involvement, Parent-Child interaction, writing readiness skills DOI: $10.7176 / \mathrm{JEP} / 11-33-12$

Publication date: November $30^{\text {th }} 2020$

\section{Introduction}

Children who are parented positively are more likely to form good adult relationships, succeed in school and find good stable employment and are less likely to suffer anxiety and depression, abuse substances and drugs, engage in risky sexual practices and be involved in crime and violence (Gould and Ward, 2015; Landry, 2014)..

Parents' involvement and quality support are crucial to holistic development of young children and their learning at schools. Parenting promotes positive social and cognitive outcomes in children in their first five years of life (National Academies of Sciences, 2016). Children's first relationships influence the acquisition of their competences, cognitive, socio-emotional and self-regulatory skills thus setting the stage for lifelong adaptation and functionality (WHO, 2004).

\section{Caregivers' Involvement in Children's Literacy}

Writing readiness skills are fundamental skills that enable pre-school children to develop the ability to hold and move a pencil fluently and effectively to produce a legible writing. Having well developed writing readiness skills promotes pre-schoolers' self-esteem and academic performance. Hand-eye coordination, Object manipulation and visual perception are some of the building blocks necessary to develop writing readiness skills in pre-schoolers. Therefore, practices such as reading and those involve the use of one or two fingers for example pocking and pointing are important in developing writing readiness skills (Kid Sense Child Development Corporation., 2020). Early competencies such as basic learning skills are acquired at very early years and are the foundations for more learning in the life-course (WHO,UNICEF and World Bank, 2018). Quality caregiver child interaction is essential in development of social, cognitive, language and literacy skills of a child which are important for his learning or performance at preschool. According to Caregiver child interactions, stimulations, and provision of ageappropriate play and communication activities promote language and literacy of children (Ministry of General Education, 2016; National Academies of Sciences, 2016).

According to Lucas, Richter and Daelmans (2017) responsive caregiving is the basis of protecting children against injury, recognizing and responding to illness, improving learning and development of trust and relationships. They argue that sensitive and responsive care provides a range of support necessary for multiple aspects of a child's learning. It is the basis for child's self-confidence and readiness to learn.

According to Britto and Limlingan (2012) supportive parenting and stimulating home environment are among the strong predictors of school performance. They argued that caregivers exhibiting warmth and affection to their children influence their development of relationships and emotional well-being required for their success in school. Warmth and affection expressed by parents to their children results to high self-esteem, improvement in academic performance, better parent-child communication and fewer psychological \& behavioural problems and happier, resilient and less anxious children (Schawtz, 2017).

A study was conducted in rural public schools in Narok county by T. Mwoma (2017) to establish factors influencing children's reading ability and whether there are differences in reading between boys and girls. The 
findings of the study revealed that having supportive parents and teachers are critical in promoting children's reading. However, the study focused on the ability of children to read not writing readiness skills as the current study.

Ashiono (2013) conducted a study on relationship between parenting style and preschool children's performance in curriculum activities in Mombasa County. The study found out that, children of authoritative parents obtained higher means score in curriculum activities than those of permissive and authoritarian parents. This can be attributed to quality interactions between authoritative parents and their children. The authoritative parents provide necessary support to their children thus enhance their learning. However, the study focused on relationship between parenting style and performance of preschool children on curriculum activities not specifically on writing readiness.

Kathomi (2015) conducted a study in Lang'ata division to determine the effects of parental involvement on literacy development of preschoolers. The finding of the study indicated an existence of a positive correlation between parental involvement and literacy development of preschoolers. However, the study focused on reading skills and not writing readiness as the current study did.

Mungai (2016) conducted a study to establish the influence of Early Childhood Education quality primary school readiness in ECE pupils in Nairobi County. The findings of the study revealed an existence of relationships between primary school readiness and teacher-pupils' interactions and also with parental involvement. He noted that positive teacher-pupils' relationships had positive while harshness and detachment had negative outcomes on pupils' school readiness. However, the study focused on the influence of caregivers' interactions on their children's gross motor. The current study sought to fill the gap by focusing on writing readiness that is directly influenced by pupils' fine motor development.

\section{Methodology}

The research employed ex post facto research design. According to Kothari (2004), ex post facto research is used to discover causes when the researcher cannot control the variables or when true experiment is not possible. The research design can be used in analysing a cause on the basis of effect. The design is more economical and less time consuming than true experiment design (Ex-Post Facto Research, n.d.; Lanip, 2013). Data was collected through questionnaire and assessment tests, summarized through frequencies, means, standard deviation, ranges and percentages then analysed through Pearson correlation coefficient. The research design was used to compare the learning achievements of children whose caregivers benefited and those who did not benefit from a parenting education program implemented by ChildFund Kenya in Ugunja Sub County.

\subsection{Location of the Study}

The study was conducted in Ugunja Sub-County in Siaya County which is in western Kenya. Findings of a survey conducted in the county revealed that only $26.5 \%$ of $36-59$ months old children in Siaya county have good literacynumeracy skill (Kenya National Bureau of Statistics, 2013). HIV/AIDS prevalence rate is also 4.2 times higher than the national prevalence rate at $24.8 \%$ hindering quality interaction between affected and infected parents and their children (National AIDS Control Council, 2016). Various organizations in collaboration with the county government implemented parenting education programs especially in Ugunja Sub County.

\subsection{Sample Techniques and Sample Size}

Purposive sampling technique was used in the selection of 21 Pre-schools that enrolled pre-schoolers benefited from parenting education program and 254 caregivers. Stratified random sampling was used in the selection of 254 out of 847 pre-school children to participate in the study.

\section{Research Findings and Discussions}

\subsection{Parent-Child Interaction and Writing Readiness of Preschool Children}

The study sought to find out whether there exists a significant relationship between parent's level of interaction and preschool children's writing readiness. Parents were asked to indicate the extent to which they interact with their preschool children. The preschool children were assigned some tasks of joining dots to form line pattern, shading of letters within the margins and drawing and colouring of pictures, to reveal their level of writing readiness The findings are indicated in Tables 1, 2, 3,4, 5 and 6.

\subsection{Interaction of Parents and their Preschool children}

The study sought to find out the level of interaction between parents and preschool children who benefited from parenting program and those who did not. The focus of the study was on provision of appropriate services to their children, showing of warmth and affection and play with their preschool children. The findings are presented in Table 1, 2 and 3. 


\subsubsection{Parents' Interaction with their Preschool children by Provision of Services}

Table 1: Interaction with Preschool children by Provision of Services

\begin{tabular}{|c|c|c|c|c|c|c|c|c|c|c|}
\hline & \multicolumn{2}{|c|}{$\begin{array}{l}\text { Strongly } \\
\text { Disagree }\end{array}$} & \multicolumn{2}{|c|}{ Disagree } & \multicolumn{2}{|c|}{ Neutral } & \multicolumn{2}{|c|}{ Agree } & \multicolumn{2}{|c|}{$\begin{array}{l}\text { Strongly } \\
\text { Agree }\end{array}$} \\
\hline & $\mathrm{f}$ & $\%$ & $\mathrm{f}$ & $\%$ & $\mathrm{f}$ & $\%$ & $\mathrm{f}$ & $\%$ & $\mathrm{f}$ & $\%$ \\
\hline $\begin{array}{l}\text { I am able to detect accurately whether the } \\
\text { child is hungry }\end{array}$ & 0 & 0 & 3 & 1.5 & 10 & 5.1 & 95 & 48.5 & 88 & 44.9 \\
\hline $\begin{array}{l}\text { I am able to detect accurately whether the } \\
\text { child is sick }\end{array}$ & 1 & 0.5 & 0 & 0 & 12 & 6.1 & 114 & 58.2 & 69 & 35.2 \\
\hline $\begin{array}{l}\text { I do provide food to the child when he/she } \\
\text { feels hungry }\end{array}$ & 5 & 2.6 & 6 & 3.1 & 23 & 11.7 & 106 & 54.1 & 56 & 28.6 \\
\hline $\begin{array}{l}\text { I take my child/children for medical } \\
\text { treatment immediately when he/she looks } \\
\text { sickling. }\end{array}$ & 12 & 6.1 & 20 & 10.2 & 23 & 11.7 & 92 & 46.9 & 49 & 25.0 \\
\hline $\begin{array}{l}\text { I ensure that my child has at least } 3 \text { writing } \\
\text { materials at home }\end{array}$ & 9 & 4.6 & 46 & 23.5 & 40 & 20.4 & 80 & 40.8 & 21 & 10.7 \\
\hline $\begin{array}{l}\text { I do read story books with/for my } \\
\text { child/children }\end{array}$ & 9 & 4.6 & 46 & 23.5 & 40 & 20.4 & 80 & 40.8 & 21 & 10.7 \\
\hline
\end{tabular}

Table 1 indicates that few (1.5\%) parents disagreed that they were able to accurately detect whether the child is hungry, $5.1 \%$ of them were not sure of themselves while majority $(48.5 \%$ and $44.5 \%)$ of them agreed and strongly agreed respectively that they had the ability to do so. The results also show that few (5 of 196) of parents strongly disagreed that they would provide food to a hungry child and small portion $(6.1 \%)$ disagreed with the statement while majority $(54.1 \%$ and $28.6 \%)$ of them agreed and strongly agreed respectively that they were providing food to their preschool children when hungry.

One of 196 parents indicated that she was not able to detect whether a child is sick, few $(6.1 \%)$ were not sure whether they could do so while majority $(58.2 \%$ and $35.2 \%)$ agreed and strongly agreed respectively that they were able to accurately detect whether the preschool child was sick. The findings also show that few (32 of 196) parents don't take their sick preschool children to the hospital immediately with $6.1 \%$ and $10.2 \%$ of them strongly disagreed and disagreed to the statement respectively. Few (23 of 196) of parents indicated that sometimes they did and sometimes did not. Majority (151 of 196) of parents indicated that they took their children for medical check-up immediately, when they looked sickling with $46.9 \%$ and $25 \%$ agreed and strongly agreed to the statement, respectively.

On the provision of writing materials, slightly more than third of parents indicated that they didn't ensure availability of at least 3 writing materials in their households. Nine of 196 parents strongly disagreed, 46 (23.5\%) of them disagreed, while $40(20 \%)$ were not sure. The finding also indicates that almost two-third of parents ensured that there were at least 3 writing materials in the households for their preschool children with 80 (40.8\%) agreed while $21(10.7 \%)$ strongly agreed. The findings also show that few $(4.6 \%)$ of parents strongly disagreed that they read story books with or for their preschool children, $46(23.5 \%)$ parents also disagreed, $40(20.4 \%)$ parents indicated that they sometimes did it.

The findings in Table 1 indicate that slightly more than three quarters $(76.5 \%)$ of the respondents had the ability to correctly understand their children's signals communicating their needs and addressed them appropriately. The findings imply that majority of the caregivers engaged in activities that promoted the physical development and eye-hand coordination of their children such as provision of writing materials, provision of food when hungry and reading with them storybooks thus boosted the development of writing readiness of their children. Therefore, most of the preschool children participated in the study were likely to have good writing readiness skills since supportive parenting and stimulating home environment is associated with performance at schools (Britto and Limlingan, 2012; Kid Sense Child Development Corporation., 2020)

\subsubsection{Parents' Interaction with their Preschool children through Warmth and Affection}

The study sought to find out whether parents displayed warmth and affection to their preschool children. Table 2 presents the findings of the study.

Table 2: Interaction by Warmth and Affection

\begin{tabular}{|l|l|l|l|l|l|l|l|l|l|l|}
\hline & \multicolumn{2}{l}{$\begin{array}{l}\text { Strongly } \\
\text { Disagree }\end{array}$} & \multicolumn{2}{l|}{ Disagree } & \multicolumn{2}{l|}{ Neutral } & \multicolumn{2}{l|}{ Agree } & \multicolumn{2}{l|}{$\begin{array}{l}\text { Strongly } \\
\text { Agree }\end{array}$} \\
\cline { 2 - 11 } & f & $\%$ & f & $\%$ & f & $\%$ & f & $\%$ & f & $\%$ \\
\hline $\begin{array}{l}\text { I do smile with/ kiss/hug/ my } \\
\text { child }\end{array}$ & 10 & 5.1 & 31 & 15.8 & 33 & 16.8 & 93 & 47.4 & 29 & 14.8 \\
\hline
\end{tabular}

The findings in Table 2 indicate that nearly two-third of parents participated in the study displayed warmth and affection to their preschool children by either smiling, kissing or hugging them. Ninety-three (47.4\%) of 196 
parents agreed, $29(14.8 \%)$ strongly agreed. A third $(33 \%)$ of the parents were neutral while almost a quarter $(20.9 \%)$ of them indicated that they didn't show warmth and affection to them with $10(5.1 \%)$ strongly disagreed and 31(15.8\%) disagreed. This implies that the development of emotions and self-esteem of most children of the respondents were being boosted thus they could be feeling secure and confident to manipulate objects in their surroundings which in turn promote development of their gross motor skills. According to Britto and Limlingan (2012) warmth and affection influence social development and emotional well-being of children which are required for their success in schools. Warmth and affection expressed by parents results to high self-esteem and improvement in academic performance (Schawtz, 2017). Therefore, their children were likely to have good writing readiness skills.

\subsubsection{Interaction through Play}

The study sought to find out whether parents interact with their preschool children through play by engaging in play and provide them with play materials. The findings are presented in Table 3

Table 3: Interaction with Preschool through Play

\begin{tabular}{|l|l|l|l|l|l|l|l|l|l|l|}
\hline & \multicolumn{2}{l|}{$\begin{array}{l}\text { Strongly } \\
\text { Disagree }\end{array}$} & \multicolumn{2}{l|}{ Disagree } & \multicolumn{2}{l|}{ Neutral } & \multicolumn{2}{l|}{ Agree } & \multicolumn{2}{l|}{$\begin{array}{l}\text { Strongly } \\
\text { Agree }\end{array}$} \\
\cline { 2 - 12 } & $\mathrm{f}$ & $\%$ & $\mathrm{f}$ & $\%$ & $\mathrm{f}$ & $\%$ & $\mathrm{f}$ & $\%$ & $\mathrm{f}$ & $\%$ \\
\hline $\begin{array}{l}\text { I do engage in outdoor plays with my } \\
\text { child/children }\end{array}$ & 12 & 6.1 & 48 & 24.5 & 33 & 16.8 & 87 & 44.4 & 16 & 8.2 \\
\hline I do provide play materials to my child & 16 & 8.2 & 36 & 18.4 & 25 & 12.8 & 80 & 40.8 & 39 & 19.9 \\
\hline
\end{tabular}

The findings in Table 3 denote that, slightly more than half $(52.6 \%)$ of parents indicated they were engaging in outdoor play with preschool children, a third (33\%) of them were neutral and nearly a third (60 of 196) of parents indicated that they didn't engage in play with preschool children The findings on 'I do provide play materials to my child' nearly two-third $(60.7 \%)$ of parents indicated that the provided play materials to the preschoolers while slightly more than a quarter $(26.6 \%)$ indicated that they didn't and $25(12.8 \%)$ of them were neutral. The finding implies that, slightly half of children of the respondents were likely to display good writing readiness skills since their caregivers engaged with them in activities that boost the development of writing readiness skills. Since parents engagement in children's activities such as playing games and provision of materials has positive effect on children's performance at schools (Mwoma, 2009; Britto and Limlingan, 2012)

\subsection{Overall Preschoolers' performance in Writing Readiness}

The level of preschool children's writing readiness skills was assessed by use of an assessment test with three sections which entailed joining of dots to form line pattern, shading of letters within the margins and drawing and colouring of pictures. The first two sections had 5 marks each and the last section had 10 marks thus the highest score that could be attained is 20 marks. The researcher converted the scores into percentages of which the highest scored was $92 \%$ while lowest was $20 \%$. Table 4 presents the findings relating to the overall performance of preschool children in writing readiness.

Table 4: Preschoolers' Performance in Writing Readiness

\begin{tabular}{|l|l|l|l|}
\hline Class Interva1 & Frequency & Mean & Percent \\
\hline $20-29$ & 16 & 56.88 & 8.3 \\
$30-39$ & 15 & 56.88 & 7.7 \\
$40-49$ & 29 & 56.88 & 14.8 \\
$50-59$ & 29 & 56.88 & 14.8 \\
$60-69$ & 68 & 56.88 & 34.7 \\
$70-79$ & 26 & 56.88 & 13.2 \\
$80-89$ & 10 & 56.88 & 5 \\
$90-99$ & 3 & 56.88 & 1.5 \\
\hline
\end{tabular}

Table 4 shows that 60 of 196 preschool children scored below the $50 \%$ mark while most $(69.2 \%)$ of them scored $50 \%$ and above. It also shows that the score achieved by many $(34.7 \%)$ preschool children compared to other scores was $64.5 \%$. The overall mean score of the 196 preschool children was $56.88 \%$. These findings denote that the level of writing readiness of most of the preschool children was high. This could be attributed to proper interactions between them and their parents as denoted by findings in table 1 since parental involvement has positive outcomes to school readiness (Mwoma, 2009; Mungai,2016; Kathomi 2015).

\subsection{Relationship between Parent-Child Interaction and Preschoolers' Writing Readiness}

The study sought to establish whether there was a significant relationship between parent child interaction and writing readiness of preschool children. Means and Standard deviation of level of interaction and writing readiness of preschool children were computed. Table 5 and 6 present the results. 
Table 5: Means and Standard Deviations level of parent-child interaction and Preschoolers' Writing Readiness

\begin{tabular}{|l|l|l|l|l|l|}
\hline & N & Minimum & Maximum & Mean & Std. Deviation \\
\hline Parent Child Interaction Level & 196 & 41.82 & 96.36 & 74.8333 & 10.47116 \\
Writing Readiness Level & 196 & 20.00 & 92.00 & 56.8776 & 16.51123 \\
Valid N (listwise) & 196 & & & & \\
\hline
\end{tabular}

Results in Table 5 shows that the minimum score of parents in interaction with their preschool children was 41.82, maximum score of 96.36 with a mean score of 74.33 and a standard deviation of 10.67 . This indicates that most of parents involved in the study had good interactions with their preschoolers. The result shows that, there was a wide range $(72 \%)$ between the highest score and lowest score of preschool children on writing readiness. However, the overall preschool children's average score 57.04 on writing readiness was above the average mark $(50 \%)$ this indicates that, majority of preschool children had high level of writing readiness. The following null hypothesis was tested using Pearson correlation coefficient to establish there was existence of a significant relationship between the two variables:

Ho1: There is no significant relationship between parent-child interactions and preschool children's level of writing readiness.

Table 6: Pearson Correlations Coefficient on Interaction and Writing readiness

\begin{tabular}{|ll|l|l|}
\hline & & Parent Child Interaction Level & Writing Readiness Level \\
\hline \multirow{4}{*}{ Parent Child Interaction Level } & Sig. (2-tailed) & & $.175^{*}$ \\
& $\mathrm{~N}$ & 196 & .014 \\
& Pearson Correlation & $.175^{*}$ & 196 \\
Writing Readiness Level & Sig. (2-tailed) & .014 & 1 \\
& $\mathrm{~N}$ & 196 & \\
& & 196 \\
\hline
\end{tabular}

*. Correlation is significant at the 0.05 level (2-tailed).

Table 6 indicates there was a significant relationship between Parent-child interaction and writing readiness where $r=0.175$ and $p=0.014<0.005$. The $P$ value 0.014 was found to be less than critical value of 0.05 . Based on this finding, the null hypothesis was rejected. The result also revealed an existence of a positive relationship between the two variables. This implies that parents with higher interaction with their children have children with high level of writing readiness than those whose parents do not interact with. The coefficient of determination was computed by squaring $r=0.175$ to determine the effect of Parent- child interaction on the writing readiness of preschoolers. The result of the computation was 0.030625 . This indicates that parent-child interaction accounts for up to $3.06 \%$ of variance in preschool children's performance in writing readiness. This implies that parents can enhance writing readiness of preschoolers by $3 \%$ by having good interaction with them.

These findings agree with the findings of Mwoma (2009) who found that fathers' involvement in children's education, influenced performance of pre-schoolers in Gucha Sub County. She found that the more fathers were involved the better the performance of their children school activities. The findings agree with the findings of Ashiono (2013) which indicated an existence of a significant relationship between authoritative parenting and pupils' performance in curriculum activities. These findings also agree with those of Obilloh (2018) who found that preschool children whose parents were more involved in their children's reading readiness activities had higher reading readiness level than those of less involved parents. Some of the activities stated by Obilloh that parents involved in included playing with children, Storytelling, reading with and for children.

\section{Conclusion}

It can be concluded that, there is a relationship between quality parent-child interactions and pre-schoolers' level of writing readiness. The higher the level of interaction preschool children experience at home, the higher their level of writing readiness at preschools.

\section{Recommendations}

i. The findings of the study revealed that preschool children experienced higher level of interaction with their caregivers, had better writing readiness skills than those experienced low level of interactions. Therefore, an integrated policy encompassing parenting education, education and family livelihood should be developed by relevant government ministries. This will facilitate the establishment of favourable conditions promoting positive interactions between caregivers and their children resulting to access of quality ECD services both at the communities and institutions levels.

ii. The findings of the current study were based on the self-report from parents. There is need for future studies on parenting to observe interaction between parents and their children at their homes to determine quality of their relationships 


\section{References}

Ashiono, B. L. (2013). Relationship between parenting styles and preschool children's performance in curriculum activities in Kisau district, Mombasa County,Kenya. Kenyatta University.

Britto, P. R., \& Limlingan, M. C. (2012). School readiness and transitions.A companion to the child friendly schools manual. https://www.unicef.org/publications/files/CFS_School_Readiness_E_web.pdf

Ex-Post Facto Research. (n.d.). http://egyankosh.ac.in/bitstream/123456789/20909/1/Unit-2.pdf

Gould, C., \& Ward, C. L. (2015). Positive parenting in South Africa: Why supporting families is key to development and violence prevention. Institute for Security Studies. https://issafrica.s3.amazonaws.com/site/uploads/PolBrief77.pdf

Kathomi, M. S. (2015). Parental involvement and literacy development of preschoolers in Lang'ata division. [University of

Nairobi]. http://erepository.uonbi.ac.ke/bitstream/handle/11295/92797/Kathomi_ParentalInvolvementandtheLiteracy DevelopmentofPreschoolersinLangataDivision.pdf? sequence $=3 \&$ isAllowed $=\mathrm{y}$

Kenya National Bureau of Statistics. (2013). Siaya County multiple indicators cluster survey 2011. https://www.google.com/search?rlz=1C1CHBF_enKE817KE817\&ei=KImjXJGJOo6xggeolaHIDg\&q=mo nitoring + situations + of + children + and + women + siaya + county $+2011 \% 2$ Bknbs\&oq $=$ monitoring + situations + of + children+and+women+siaya+county+2011\%2Bknbs\&gs_l=psy-ab.3...7744.9439..9943

Kid Sense Child Development Corporation. (2020). Writing readiness (pre-writing) skills. https://childdevelopment.com.au/areas-of-concern/writing-readiness-pre-writing-skills/

Kothari, C. R. (2004). Research methodology: Methods and techniques. (3rd ed.). New Age International (p) Limited.

Landry, S. H. (2014). The roles of parents in early childhood learning. Encyclopiedia on Early Childhood Development. http://www.child-encyclopedia.com/parenting-skills/according-experts/role-parents-earlychildhood-learning

Lucas, J. E., Richter, L. M., \& Daelmans, B. (2017). Care for child development: An intervention in support for responsive caregiving and early development. Wiley Online Library. https://onlinelibrary.wiley.com/doi/pdf/10.1111/cch.12544

Ministry of General Education, R. of Z. (2016). Early Learning and Development Standards (ELDS) and school reradiness. https://itacec.org/ece/document/learning_resources/2017/ELDS_Final_Report_March2017.pdf

Mungai, D. N. (2016). Influence of quality of Early Childhood Education on primäry school readiness in preschool pupils in Nairobi County,Kenya. [University Of Nairobi]. https://pdfs.semanticscholar.org/4afc/2cdf02a3486f624ae52aeec763860a95ad31.pdf

Mwoma, B. T. (2009). Paternal involvement in children's education: An implication of children's performance at preschool in Gucha District in Kenya. Kenyatta University.

Mwoma, T. (2017). Children's reading ability in early primary schooling: challanges for a rural community. Issues in Educational Research, 2(27), 327-364. https://www.researchgate.net/publication/316253281_Children's_reading_ability_in_early_primary_schooli ng_Challenges_for_a_Kenyan_rural_community

National Academies of Sciences, E. and M. (2016). Parenting matters; Supporting of children of age 0-8. https://doi.org/10.17226/21868

Obilloh, W. O. (2018). Family characteristics influencing reading of pupils in pre-primary schools in Siaya County, Kenya. [Kenyatta University]. https://ir-library.ku.ac.ke/bitstream/handle/123456789/18579/Family characteristics influencing reading....pdf? sequence $=1 \&$ is Allowed $=\mathrm{y}$

Schawtz, S. (2017). How parent's affection shapes a child's happiness for life. https://www.gottman.com/blog/how-a-parents-affection-shapes-a-childs-happiness-for-life/

WHO, UNICEF, \& World Bank Group. (2018). Nurturing care for early childhood development: A framework for healping children survive and thrive to transform health and human potential. https://apps.who.int/iris/bitstream/handle/10665/272603/9789241514064-eng.pdf?ua=1 